\title{
REAPROVEITAMENTO DA CASCA DE BANANA PARA TRATAMENTO DE SOLUÇÕES AQUOSAS CONTENDO COBRE
}

\author{
K. S. G. C. OLIVEIRA ${ }^{1}$, P. H. T. D. CABRAL ${ }^{1}$, R. R. M. da SILVA ${ }^{1}$, C. T. DIAS ${ }^{1}$ e A. P. F. \\ M. de URZEDO ${ }^{1}$ \\ ${ }^{1}$ Universidade Federal de São João del-Rei, Departamento de Engenharia Química \\ E-mail para contato: kaiquesg.eq@gmail.com
}

\begin{abstract}
RESUMO - A utilização de biossorventes apresenta-se como uma atraente alternativa para a resolução de alguns dos problemas ambientais enfrentados atualmente. Neste trabalho estudou-se a adsorção de íons cobre através da farinha da casca de banana, avaliando os efeitos do tempo de adsorção, da massa e tipo de adsorvente através do planejamento experimental. A farinha in natura apresentou capacidade de remoção de íon cobre significativa, podendo ser efetivo seu uso sem pré-tratamento em efluentes com concentrações baixas de $\mathrm{Cu}^{2+}$. Segundo os resultados estatísticos, a porcentagem de remoção de íon cobre variou de $37,1 \%$ a $98,6 \%$ entre os experimentos. Observaram-se efeitos mais significativos no aumento da porcentagem de $\mathrm{Cu}^{2+}$ adsorvido, quando se utilizou a farinha sob tratamento térmico e com excesso de massa. Houve uma redução considerável na concentração de íon cobre inicial em todos os experimentos.
\end{abstract}

\section{INTRODUÇÃO}

A contaminação em ambientes aquáticos por metais pesados é um problema preocupante. Além de não serem biodegradáveis, esses contaminantes são altamente tóxicos e bioacumulativos (Cabukdhara; Nema, 2012). Quando descartados em níveis superiores ao limite da legislação podem provocar além disso, a mortalidade ou até mesmo a extinção de espécies aquáticas, além de comprometer o abastecimento de água da população. Assim como ocorreu no acidente da barragem de Fundão em 2015, na cidade Mariana, Minas Gerais, considerado como o maior desastre ambiental ocorrido no Brasil (Freitas et al., 2016).

Dentre os métodos de tratamento convencionais existentes, a biossorção destaca-se como um método simples e não dispendioso, além de ser eficaz na remoção de metais pesados (Coelho et al., 2014). O processo é caracterizado pela transferência de massa de uma fase fluida para a superfície de um sólido, denominado bioadsorvente (Bugiereck et al., 2015).

O Brasil é um dos maiores consumidores mundiais de banana (Borges; Souza, 2004), porém sua casca geralmente é descartada sem reaproveitamento. A utilização da casca de banana como adsorvente, além de criar um destino apropriado e sustentável para os resíduos produzidos pela agroindústria, é considerada como uma boa alternativa para o tratamento de efluentes contaminados, já que se trata de um material de baixo custo e que apresenta afinidade por compostos orgânicos e metais tóxicos (Martins et al., 2015). 
Desta forma, este trabalho visa investigar a eficiência de remoção de cobre de uma solução sintética de sulfato de cobre $\left(\mathrm{CuSO}_{4}\right)$ através da técnica de adsorção utilizando-se a farinha da casca de banana como adsorvente. O trabalho emprega um planejamento experimental, onde a quantidade de cobre removida será determinada em função do tempo de adsorção, da massa e do tipo de farinha utilizada (in natura, quimicamente tratada e pirolisada).

\section{METODOLOGIA EXPERIMENTAL}

\subsection{Preparação do bioadsorvente}

Utilizou-se a casca de banana como bioadsorvente, resíduo oriundo do restaurante universitário da Universidade Federal de São João del-Rei e da alimentação pessoal de estudantes. Aproximadamente $900 \mathrm{~g}$ de cascas de bananas foram lavadas com água destilada, cortadas e secas em estufa a $60^{\circ} \mathrm{C}$ por 24 horas seguido de $100{ }^{\circ} \mathrm{C}$ por 48 horas. Após isso, as cascas foram cominuídas em um liquidificador doméstico, reservando-se a farinha com partículas entre 60 e 100 mesh, onde a maior parte do material ficou retida.

\subsection{Tratamento químico e térmico da casca de banana}

Cerca de $50 \mathrm{~g}$ da farinha foram tratadas com uma proporção de $1 \mathrm{~L}$ de solução de $\mathrm{NaOH}\left(0,5\right.$ mol. $\left.\mathrm{L}^{-1}\right)$, a $25^{\circ} \mathrm{C}$, durante uma hora, com agitação mecânica. Logo após, esta farinha foi lavada com água destilada repetidas vezes até que o $\mathrm{pH}$ da água de lavagem apresentasse valor próximo do neutro. A amostra final foi levada para uma estufa a $50^{\circ} \mathrm{C}$ durante 48 horas e por mais 24 horas, a $70{ }^{\circ} \mathrm{C}$. Para o tratamento químico do adsorvente in natura, aproximadamente $60 \mathrm{~g}$ de farinha foram pirolisadas à temperatura de $600^{\circ} \mathrm{C}$ por duas horas, em atmosfera inerte.

\subsection{Preparo da solução de sulfato de cobre II}

Para a realização dos experimentos de adsorção, preparou-se uma solução com concentração de $40 \mathrm{mg} . \mathrm{L}^{-1}$ de sulfato de cobre II anidro (98\%). As concentrações residuais de íons $\mathrm{Cu}^{2+}$ de todas as soluções foram monitoradas pela espectrometria de absorção atômica.

\subsection{Planejamento Experimental}

Tabela 1 - Fatores e níveis de estudo

\begin{tabular}{|c|c|c|c|}
\hline Níveis & $\begin{array}{c}\text { Massa da } \\
\text { farinha }(\mathrm{mg})\end{array}$ & $\begin{array}{c}\text { Tempo de } \\
\text { adsorção (min) }\end{array}$ & Tipo de farinha \\
\hline \hline-1 & 30 & 30 & in natura \\
\hline 0 & 50 & 45 & tratada \\
\hline 1 & 70 & 60 & pirolisada \\
\hline
\end{tabular}

Para otimizar o método de remoção do íon cobre em solução aquosa utilizando farinha de casca de banana, utilizou-se o planejamento experimental fatorial Box-Bennken com três fatores: massa de farinha $\left(\mathrm{x}_{1}\right)$, tempo $\left(\mathrm{x}_{2}\right)$ e tipo de farinha $\left(\mathrm{x}_{3}\right)$. A Tabela 1 contém as 
variáveis de estudo e os respectivos níveis estabelecidos. O planejamento experimental foi elaborado com três experimentos replicados no ponto central, totalizando 15 experimentos.

\section{RESULTADOS E DISCUSSÃO}

\subsection{Resultados experimentais de adsorção}

Os resultados de porcentagem de adsorção de íon cobre em cada experimento são apresentados na Tabela 2 abaixo.

Tabela 2 - Matriz padrão para o planejamento Box-Behnken e resultados obtidos

\begin{tabular}{|c|c|c|c|c|c|}
\hline Experimentos & $\begin{array}{c}\text { Massa da } \\
\text { farinha }(\mathrm{mg})\end{array}$ & $\begin{array}{c}\text { Tempo de } \\
\text { adsorção (min) }\end{array}$ & Tipo de farinha & $\begin{array}{c}\text { Porcentagem de } \\
\mathrm{Cu}^{2+} \text { adsorvido } \\
(\%)\end{array}$ & $\begin{array}{c}\text { Concentração } \\
\text { final de } \mathrm{Cu}^{2+} \\
\left(\mathrm{mg.L}^{-1}\right)\end{array}$ \\
\hline \hline 1 & 30 & 30 & tratada & 67,4 & 13,0 \\
\hline 2 & 70 & 30 & tratada & 94,8 & 2,1 \\
\hline 3 & 30 & 60 & tratada & 71,4 & 11,4 \\
\hline 4 & 70 & 60 & tratada & 94,5 & 2,2 \\
\hline 5 & 30 & 45 & in natura & 37,1 & 25,2 \\
\hline 6 & 70 & 45 & in natura & 46,9 & 21,2 \\
\hline 7 & 30 & 45 & pirolisada & 98,6 & 0,5 \\
\hline 8 & 70 & 45 & pirolisada & 97,6 & 1,0 \\
\hline 9 & 50 & 30 & in natura & 46,2 & 21,5 \\
\hline 10 & 50 & 60 & in natura & 49,6 & 20,5 \\
\hline 11 & 50 & 30 & pirolisada & 98,3 & 0,7 \\
\hline 12 & 50 & 60 & pirolisada & 98,6 & 0,6 \\
\hline 13 & 50 & 45 & tratada & 89,5 & 4,2 \\
\hline 14 & 50 & 45 & tratada & 86,4 & 5,4 \\
\hline 15 & 50 & 45 & tratada & 90,8 & 3,7 \\
\hline
\end{tabular}

Figura 1 - Gráfico da concentração final de íon cobre na solução para cada experimento.

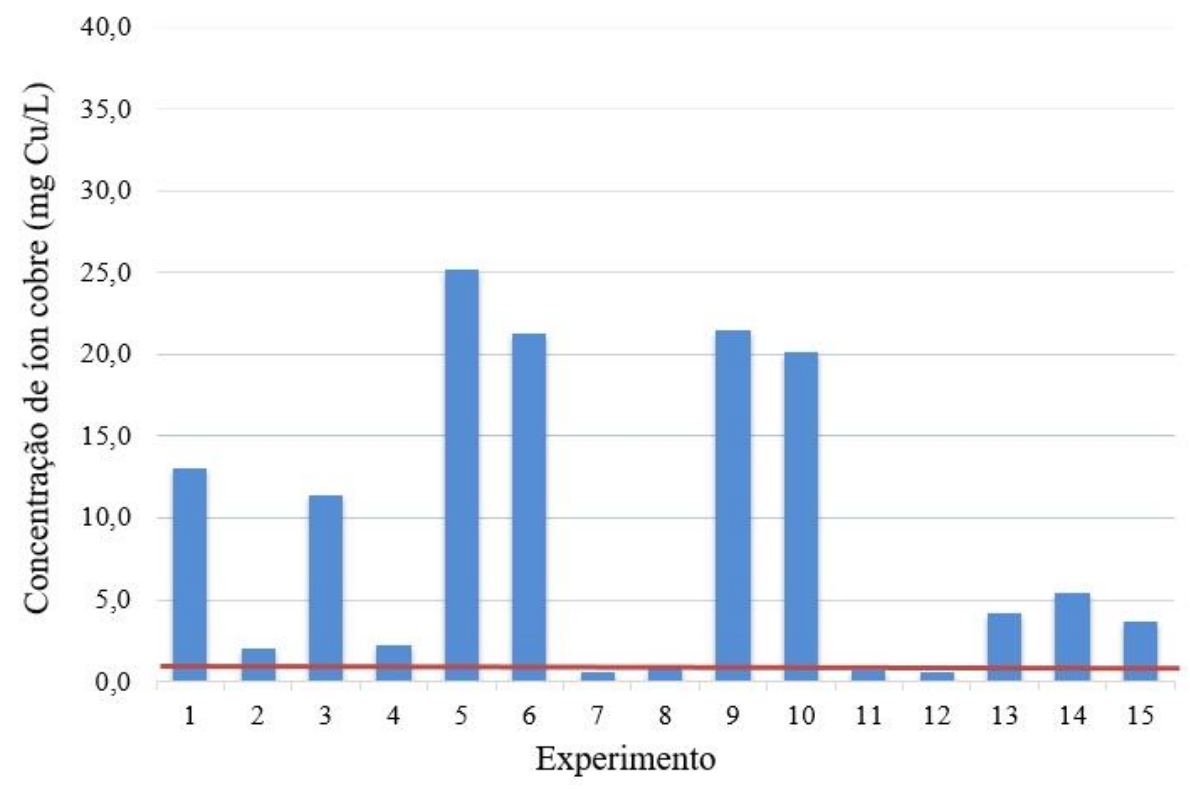


No gráfico de barras apresentado na Figura 1, podemos comparar a concentração final da solução para todos os experimentos. A concentração máxima estabelecida pelo CONAMA (Resolução No 357 de 2005), de 1,0 mg...-1, está representada como uma linha vermelha. Podemos observar que houve uma redução na concentração de íon cobre inicial considerável em todos os experimentos. Os experimentos $7,8,11$, e 12, realizados com a farinha pirolisada, se adequaram à legislação. A pirólise modifica fortemente as características estruturais da biomassa, tais como o aumento da micro e macroporosidade, disponibilizando um número maior de sítios para abrigar o $\mathrm{Cu}^{2+}$ (Lehmann; Joseph, 2009).

Vale salientar que os experimentos 2, 4 e 15 chegaram próximos de se adequar a legislação, adsorvendo mais de $90 \%$ de $\mathrm{Cu}^{2+}$. O aumento do rendimento através do tratamento químico com $\mathrm{NaOH}$ promove a mercerização do complexo lignocelulósicos da biomassa, aumentando a área superficial e deixando os sítios do material mais ativos e expostos para a adsorver o $\mathrm{Cu}^{2+}$ (Paschoal et al., 2009). Na concentração inicial de $40 \mathrm{mg}$ de $\mathrm{Cu}^{2+}$ por litro, a farinha in natura não atingiu as exigências, apesar de apresentar um grande potencial de adsorção, chegando próximo de 50\% de remoção de íon cobre no experimento 10.

\subsection{Resultados da análise estatística dos dados}

A porcentagem de remoção de íons cobre variou de 37,1 a 98,6\% entre os experimentos. A Tabela 3 reúne os dados da análise dos efeitos, estimativa do erro padrão e o teste $t$ de Student para a porcentagem de remoção de $\mathrm{Cu}^{2+}(\mathrm{y})$.

Tabela 3 - Estimativa dos Efeitos, erros padrão, teste $t$ de Student para a porcentagem de remoção de $\mathrm{Cu}^{2+}$ de acordo com o planejamento Box-Behnken

\begin{tabular}{|c|c|c|c|c|}
\hline Variáveis & Efeitos & Erros-padrão & Valores-t & p-value \\
\hline \hline Média global & 75,08 & $\pm 0,65$ & & 0,000076 \\
\hline Massa da Farinha $\left(\mathrm{x}_{1}\right)$ & 14,85 & $\pm 1,60$ & 9,275 & 0,011426 \\
\hline Massa da Farinha $\left(\mathrm{x}_{1}{ }^{2}\right)$ & 5,00 & $\pm 1,18$ & 4,250 & 0,051148 \\
\hline Tempo de Adsorção $\left(\mathrm{x}_{2}\right)$ & 1,85 & $\pm 1,60$ & 1,157 & 0,366665 \\
\hline Tempo de Adsorção $\left(\mathrm{x}_{2}{ }^{2}\right)$ & 1,88 & $\pm 1,18$ & 1,594 & 0,252004 \\
\hline Tipo de Farinha $\left(\mathrm{x}_{3}\right)$ & 53,33 & $\pm 1,60$ & 33,361 & 0,000897 \\
\hline Tipo de Farinha $\left(\mathrm{x}_{3}{ }^{2}\right)$ & 13,85 & $\pm 1,18$ & 11,733 & 0,007138 \\
\hline $\mathrm{x}_{1} \mathrm{x}_{2}$ & $-2,15$ & $\pm 2,26$ & $-0,951$ & 0,441935 \\
\hline $\mathrm{x}_{1} \mathrm{x}_{3}$ & $-5,40$ & $\pm 2,26$ & $-2,389$ & 0,139490 \\
\hline $\mathrm{x}_{2} \mathrm{x}_{3}$ & $-1,55$ & $\pm 2,26$ & $-0,686$ & 0,563726 \\
\hline
\end{tabular}

Verificou-se que os efeitos principais da massa de farinha $\left(\mathrm{x}_{1}\right)$, tipo de farinha $\left(\mathrm{x}_{3}\right)$ e $\mathrm{o}$ efeito de segunda ordem do tipo de farinha $\left(\mathrm{x}_{3}{ }^{2}\right)$ foram estatisticamente significativos, já que $\mathrm{p}<0,05$. O efeito mais importante foi verificado para o tipo de farinha $(53,33)$ seguida da massa de farinha $(14,82)$, cujo efeito está em consonância com os resultados descritos na literatura para sistemas similares (Cruz Junior, 2010; Salvador, 2009).

O efeito significativo para a variável $\mathrm{x}_{1}$ é de fácil compreensão, pois quanto maior a quantidade de material disponível para a biossorção, maior será a área superficial e, portanto, maior o número de sítios de adsorção. Entretanto, o tempo de adsorção não se mostrou estatisticamente significativo, apesar que resultados da literatura mostram o efeito contrário 
em sistemas similares (Martins et al., 2015). Considerou-se a hipótese de que os níveis estabelecidos para a variável $x_{2}$ não foram adequados, inviabilizando a detecção da flutuação dessa variável nos experimentos.

Com base nos resultados e na Figura 2, observa-se um aumento da porcentagem de $\mathrm{Cu}^{2+}$ adsorvido, quando se tem um excesso de massa de farinha e utilização da farinha pirolisada, em comparação aos demais tipos. A validade do modelo foi constatada por meio de análise de variância, cujo valor de Lack of Fit obteve p-value > 0,05, portanto, o modelo não apresentou falta de ajuste. O coeficiente de correlação $\left(\mathrm{R}^{2}\right)$ foi de 0,97 , informando que os dados observados se ajustaram bem aos dados preditos. O modelo é expresso pela Equação 1, onde y é a porcentagem de $\mathrm{Cu}^{2+}$ adsorvido, $\mathrm{x}_{1}$ e $\mathrm{x}_{3}$ representam a massa de farinha e tipo de farinha respectivamente.

$$
y=75,08+14,82 x_{1}+53,33 x_{3}+5,0 x_{1}^{2}+13,85 x_{3}^{2}
$$

Figura 2 - Superfície de resposta para a porcentagem de íon cobre descrita pelo modelo.

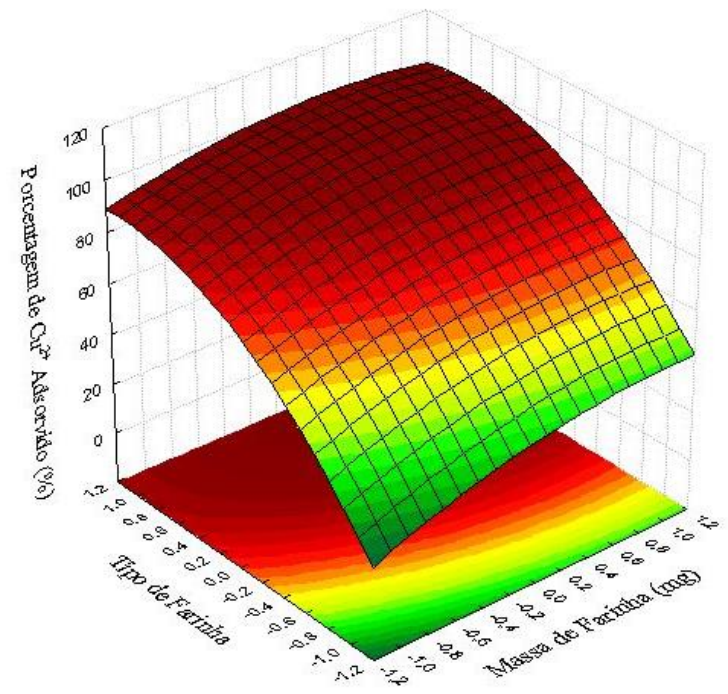

\section{CONCLUSÕES}

A produção de bioadsorventes a partir de resíduos da indústria alimentícia, como a casca de banana, mostrou-se possível, apresentando resultados satisfatórios e de baixo custo para o tratamento de efluentes contendo metais. Observou-se que as farinhas da casca de banana tratada e pirolisada demonstraram aumento na eficiência de remoção de íons cobre em efluentes sintéticos, comparados a farinha in natura. Entretanto, somente a farinha pirolisada conseguiu atender a legislação vigente, conseguindo adsorver grandes quantidades de $\mathrm{Cu}^{2+}$, de forma que as soluções residuais apresentaram concentrações de íons $\mathrm{Cu}$ menores que $1 \mathrm{mg} . \mathrm{L}^{-1}$.

$\mathrm{O}$ uso de ferramentas estatísticas mostrou ser útil para verificar a influência dos fatores testados (massa de farinha, tempo de adsorção e tipo de farinha) na porcentagem de íons cobre adsorvidos. O coeficiente de correlação $\mathrm{R}^{2}$ indica que $97 \%$ dos valores experimentais obtidos são preditos pelo modelo, o que demonstra sua adequação aos dados experimentais. 


\section{REFERÊNCIAS}

BORGES, A. L.; SOUZA, L. S. O cultivo da bananeira. Cruz das Almas: Embrapa Mandioca e Fruticultura, 2004.

BUGIERECK, A. M.; BEHLING, S. M.; FIORI, M. A.; MELLO, J. M. M. de; COLPANI, G. L.; MAGRO, J. D. Adsorção de corante catiônico por carvão ativado de casca de banana. Blucher Chem. Eng. Proc., v. 1, n. 2, p. 8246-8253, 2015.

CHABUKDHARA, M.; NEMA, A. K. Assessment of heavy metal contamination in Hindon River sediments: A chemometric and geochemical approach. Chemosphere, v. 87, n. 8, p.945-953, 2012.

COELHO, G. F.; JÚNIOR, A. C. G.; SOUZA, R. F. B. de; SCHWANTES, D.; MIOLA, A. J.; DOMINGUES, C. V. R. Uso de técnicas de adsorção utilizando resíduos agroindustriais na remoção de contaminantes em águas. J. Agron. Scien., Umuarama, v. 3, p. 291-317, 2014.

CONSELHO NACIONAL DO MEIO AMBIENTE. Dispõe sobre a classificação dos corpos de água e diretrizes ambientais para o seu enquadramento, bem como estabelece as condições e padrões de lançamento de efluentes, e dá outras providências. Resolução n. 357, de 17 de março de 2005. Diário Oficial da União. Brasília, 2005.

CRUZ JUNIOR, O. F. Produção de carvão ativado a partir de produtos residuais de espécies nativas da região amazônica. Programa de Pós-Graduação em Engenharia Mecânica e de Materiais. Universidade Tecnológica Federal do Paraná, Curitiba, p. 62-71, 2010.

FREITAS, C. M. de; SILVA, M. A. da; MENEZES, F. C. de. O desastre na barragem de mineração da Samarco: fratura exposta dos limites do Brasil na redução de risco de desastres. Ciência e Cultura, v. 68, n. 3, p. 25-30, 2016.

LEHMANN, J.; JOSEPH, S. Biochar for enviromental management: Science and Technology. Londres: Editora Earthscan, 2009.

MARTINS, W. A.; OLIVEIRA, A. M. B. M. de; MORAIS, C. E. P. de; COELHO, L. F. de O.; MEDEIROS, J. F. de. Reaproveitamento de resíduos agroindustriais de casca banana para tratamento de efluentes. Revista Verde de Agroecologia e Desenvolvimento Sustentável, v. 10, n. 1, p. 96-102, 2015.

PASCHOAL, E. C.; SANTOS, V. C. G. dos; DRAGUNSKI, D. C. Utilização da casca de banana para a adsorção de Cobre. $32^{a}$ Reunião Anual da Semana Brasileira de Química. Fortaleza, 2009.

SALVADOR, G. Estudo de adsorção de cobre (II) usando como adsorvente pó de casca de coco verde ativada com hidróxido de sódio. Universidade Federal de Santa Catarina, Centro de Ciências Físicas e Matemáticas. Florianópolis, 2009. 